\title{
Espacios de creación \\ o "makerespaces" \\ en la formación de profesores del \\ Grado de Educación Infantil y Primaria
}

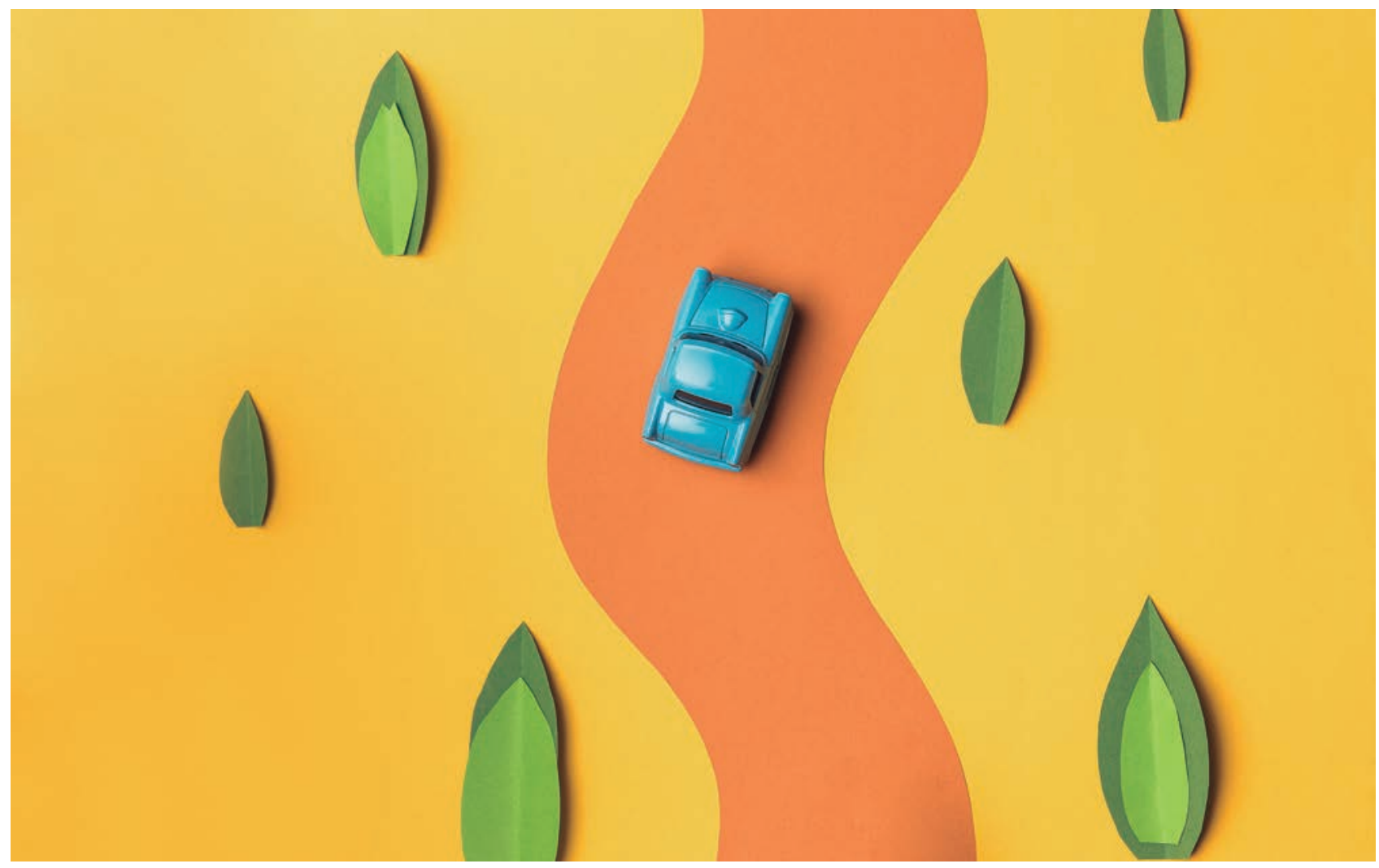

En este artículo se muestra la experiencia llevada a cabo en asignaturas de los Grados de Educación Infantil y Educación Primaria en la Universidad Pontificia Comillas, en las cuales los estudiantes aprenden a dar respuesta a retos educativos mediante la fabricación de materiales y recursos de apoyo. La experiencia se completa con el envío de los materiales creados a centros con pocos recursos económicos a través de una experiencia de aprendizaje-servicio. 


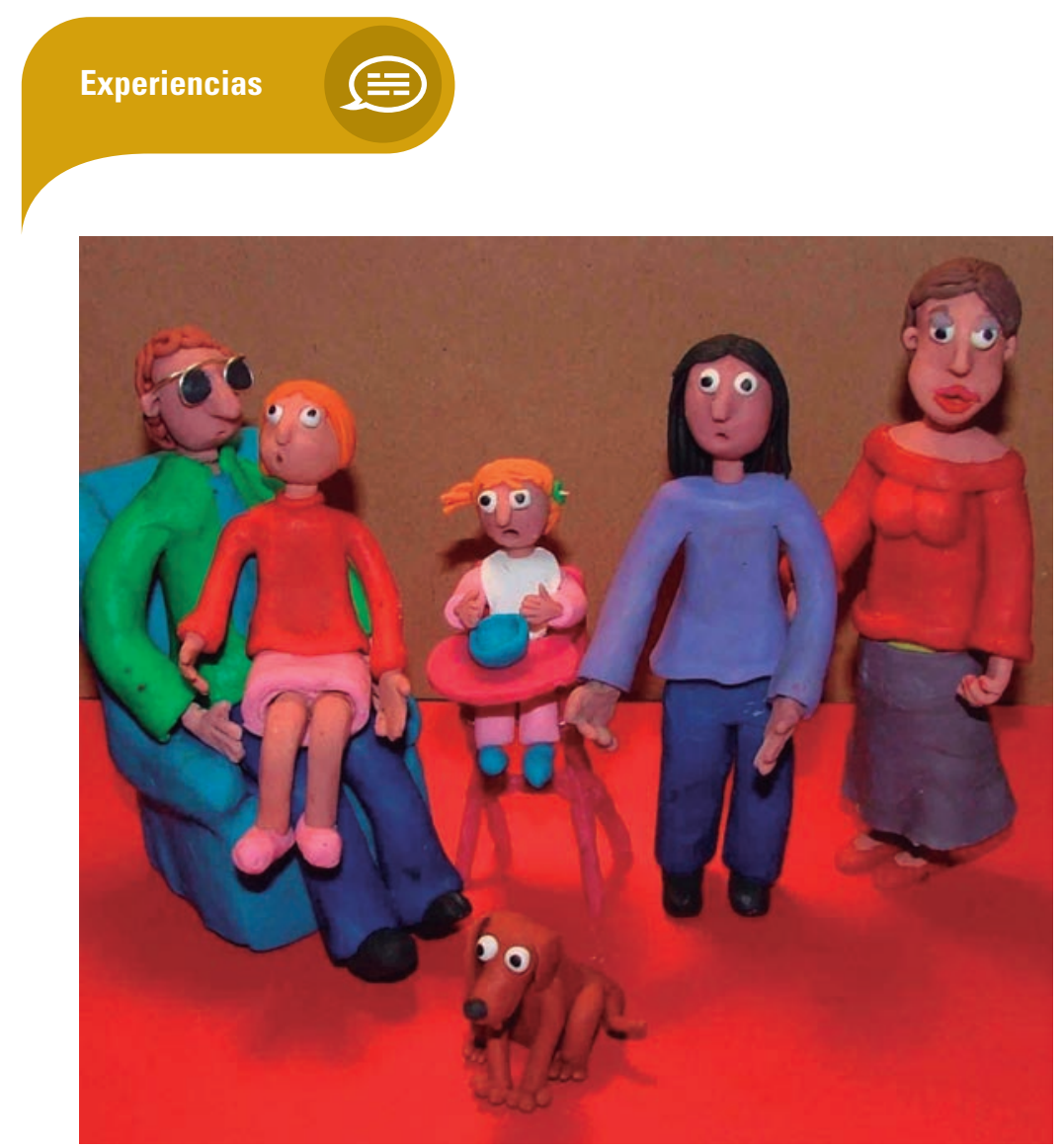

Hacer cosas con nuestras propias manos ayuda a tener experiencias más vívidas

\section{Los materiales y recursos educativos/didácticos}

Aunque conceptualmente existe mucha confusión, ya que diversos autores de reconocido prestigio definen los materiales, recursos, medios y estrategias en el contexto educativo de formas muy diferentes y a veces poco diferenciadas, con el fin de compartir un lenguaje común, en este artículo se va a hablar de materiales como aquellos medios físicos (o tecnológicos) que pueden usarse en el proceso formativo y que tienen una estructura didáctica que posibilita adquirir competencias y objetivos, siendo facilitadores de los mismos. Los recursos educativos hacen referencia a las herramientas que se usan en los procesos educativos, entre las que se encuentran los materiales, aunque no solamente.

Si consideramos que la intervención educativa debe ser tan individualizada como lo requiera el alumno, cobra especial importancia poder disponer de recursos materiales ad hoc para trabajar en escenarios personalizados.

\section{La creación de materiales educativos}

Durante toda la historia de la enseñanza los profesores han creado sus propios materiales didácticos con el fin de apoyar el aprendizaje de aquellos alumnos cuyas características específicas les obstaculi- zaban la progresión en condiciones similares al resto de sus compañeros.

Además de los docentes de aula, se considera que es el profesor de Pedagogía Terapéutica $(P T)^{1}$, la figura que debería hacerse cargo de la creación de recursos y materiales ad hoc para los alumnos que lo requieran.

Muchos profesores y profesores de PT, a la vista del desembolso necesario para adquirir materiales o la inadecuación de los mismos, recurren a crear, diseñar y fabricar aquellos recursos que les son de utilidad en un momento concreto. Además, el uso de la red facilita los conocimientos necesarios para su implementación y hacen que pueda realizarse casi cualquier recurso educativo, siempre que se tengan los conocimientos profesionales y técnicos previos sobre las necesidades de los alumnos y cómo trabajar con ellos.

Desde la perspectiva de la formación de futuros maestros, hacer materiales didácticos los enfrenta a un reto cognitivo ya que, con frecuencia, lo que está en nuestra cabeza (incluso, podemos visualizarlo con nuestra imaginación) al fabricarlo o implementarlo "no funciona" y eso solo podemos saberlo si pasamos del mundo de las ideas al de la realidad. Podríamos decir que con estas actividades se modifican las estrategias de pensamiento de los estudiantes: "La Educación Maker tiene como objetivo proporcionar a los estudiantes la autonomía necesaria para explorar sus propias ideas y verse a sí mismos como personas que pueden imaginar, crear, construir y resolver problemas"?

\section{Legislación}

Es una realidad en nuestras aulas que los profesores no siempre disponen de los

1 Un maestro o profesor de PT es aquel que está especializado en la atención en el aula ordinaria o de apoyo a los estudiantes con necesidades educativas especiales o dificultades de aprendizaje. Los profesionales PT deben ser maestros con una formación complementaria que les posibilita este apoyo.

2 Recuperado de: https://bit.ly/2IdwbZw 
recursos necesarios para que todos los alumnos puedan progresar de la forma adecuada con materiales ad hoc a sus necesidades, ya sean estas permanentes o transitorias.

Los alumnos con necesidades de apoyo educativo por sus características personales, sociales o psicológicas requieren estrategias específicas, recursos adaptados, frecuentes repeticiones y materiales muy diversos que los enfrenten a situaciones similares y les permitan la generalización en sus aprendizajes y la aplicación de estos en diferentes contextos.

Resulta tan importante este tema que aparece contemplado en la ORDEN 547/2019, de 24 de febrero, de la Consejería de Educación e Investigación de la Comunidad de Madrid por la que se regulan los criterios para la organización y funcionamiento de la orientación en Educación Primaria en centros privados concertados. Así, en el artículo 2, apartado e) del capítulo 2, se menciona de forma expresa como función de los maestros de PT el "Elaborar, adaptar y difundir materiales e instrumentos que sean de utilidad a la comunidad educativa para la atención a la diversidad del alumnado y para la acción tutorial" 3 . En esta misma orden, en su artículo 4, se menciona que dentro de la jornada laboral del PT debe estar contemplada la "preparación de materiales".

En este sentido, deben conocer los materiales existentes en el mercado, identificar carencias, valorar la posibilidad del rediseño y, en su caso, elaborar y crear sus propios materiales educativos.

Los estudiantes de PT deberían verse enfrentados, antes de acabar sus estudios, a situaciones cuasi reales mediante la realización de retos cognitivos que les acerquen a actividades cercanas a su futura vida laboral y que sean percibidas como tales por los estudiantes de forma que los aprendizajes generados resulten significativos, al adquirir competencias nuevas.

3 https://www.bocm.es/boletin/CM_Orden_ BOCM/2019/02/28/BOCM-20190228-19.PDF

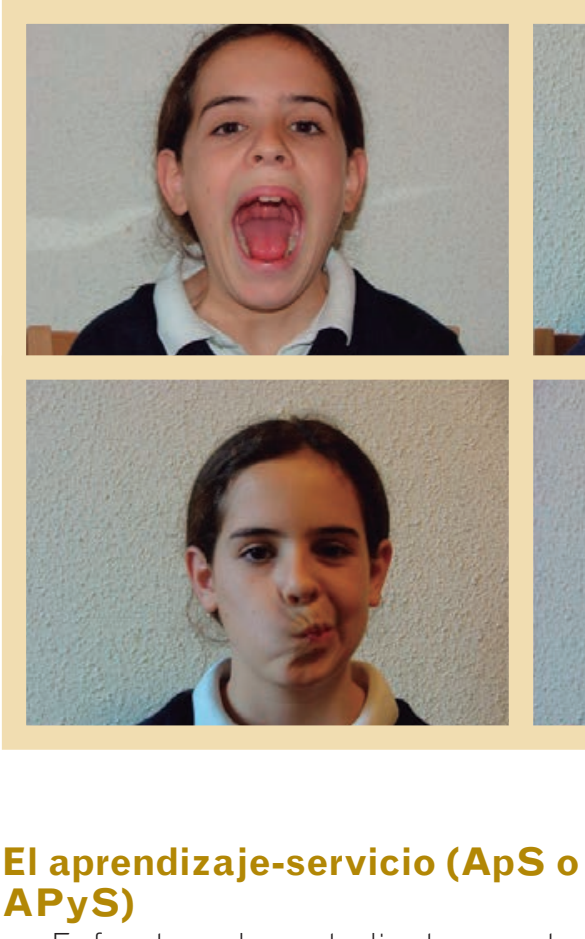

Enfrentar a los estudiantes a estas situaciones cuasi reales no siempre resulta sencillo desde un aula universitaria. Por ello, en la experiencia que se presenta, se ha vinculado la asignatura a una experiencia de aprendizaje-servicio.

El APyS se caracteriza porque los estudiantes deben implicarse en una experiencia de ayuda social, a la vez que realizan un aprendizaje curricular ${ }^{4}$, estimulando el esfuerzo, la responsabilidad y el compromiso solidario ${ }^{5}$.

En palabras de Roser Batlle ${ }^{6}$, el ApS es:

7 Un método para unir el aprendizaje con el compromiso social.

ᄀ Una forma de aplicar conocimientos y habilidades en una práctica solidaria.

入 Una forma de hacer conscientes a las personas implicadas de que son ciudadanos capaces de provocar cambios en su entorno.

El ApS estimula la solidaridad y el compromiso, hace más responsables a

4 La unión de estos dos aspectos en una única actividad es lo que diferencia fundamentalmente el ApS del voluntariado.

5 https://aprendizajeservicio.net/que-es-el-aps/

6 https://roserbatlle.net/aprendizaje-servicio/ 

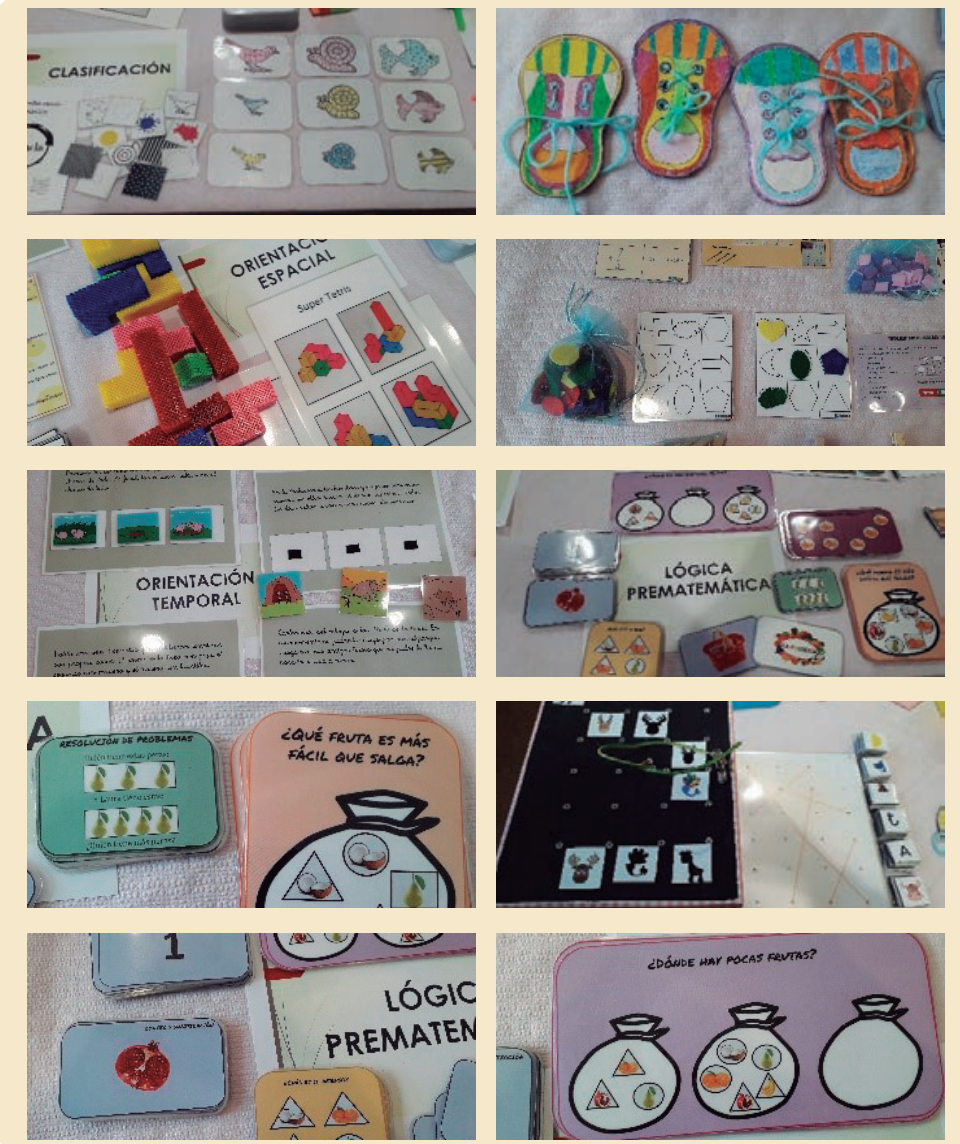

Materiales realizados por los alumnos para enviar a Perú los estudiantes y da un sentido diferente a sus propios aprendizajes.

Pensamos que sentirse útil a los demás, ser conscientes de que ayudamos a otros que están en situación de desventaja o que tienen problemas, va a hacer que nuestros futuros maestros estén mejor formados tanto profesional como personalmente y, sobre todo, les va a hacer sentir más felices, ya que "como seres humanos estamos programados a ser generosos y servir a los demás"?.

\section{Diseño y creación de materiales como parte de la formación de futuros maestros de Pedagogía Terapéutica}

Desde la perspectiva mostrada hasta ahora, se planificó la asignatura de Recursos educativos para alumnos con discapacidad o dificultades de aprendizaje durante los cursos 2018-19 y 2019-20 en la Mención en Pedagogía Terapéutica de los Grados de Educación: debían crear materiales y, a la vez, participar en una experiencia de ApS, de tal manera que

7 https://bit.ly/32Itjgy lo que realizaran en el aula pudiera ser usado en centros educativos que carecían de recursos materiales adecuados o suficientes.

Para realizar este trabajo, los estudiantes de cada curso se dividieron en 4 grupos (entre 4 y 6 estudiantes), en ambos grados.

\section{Curso 2018-19}

Durante este curso se inició la experiencia y en él los alumnos hicieron materiales para enviar a un gabinete psicopedagógico en Perú. Los educadores seleccionaron aquellos materiales que podían necesitar y cada uno de los equipos de trabajo eligió dos tipos de materiales para desarrollarlos (esquema 1):

7 Materiales 1: durante 2 meses, cada grupo debía realizar materiales para trabajar una única área de estimulación (atención, ritmo, memoria...), creando por parejas recursos concretos que permitieran la estimulación del área seleccionada por el equipo. De este modo, cada grupo trabajó un área de estimulación concreta de tres formas distintas (una por cada par de estudiantes), ayudándose entre sí. Una vez hechos los materiales, entre todos debían buscar otras formas de trabajar el área asignada con esos mismos materiales, siguiendo un criterio de dificultad creciente ${ }^{8}$.

त Materiales 2: durante otros dos meses, tuvieron que realizar materiales para otra área diferente. En este caso, todos los estudiantes de cada grupo debían realizar un único material de estimulación, pensando diversas formas de usarlo, entre las cuales, nece-

8 Este resultó ser un aspecto muy complicado y, sin embargo, fundamental para los objetivos de la asignatura ya que supone pensar y reflexionar sobre lo realizado con el fin de mejorar su utilidad, facilitar la generalización de aprendizajes, rentabilizar el esfuerzo realizado (tiempo, desembolso económico...) y caer en la cuenta de que siempre, si pensamos sobre ello, los materiales pueden resultar muy versátiles. 
Esquema 1. Esquema de trabajo durante el curso 2008-2019 ejemplificado con un único grupo

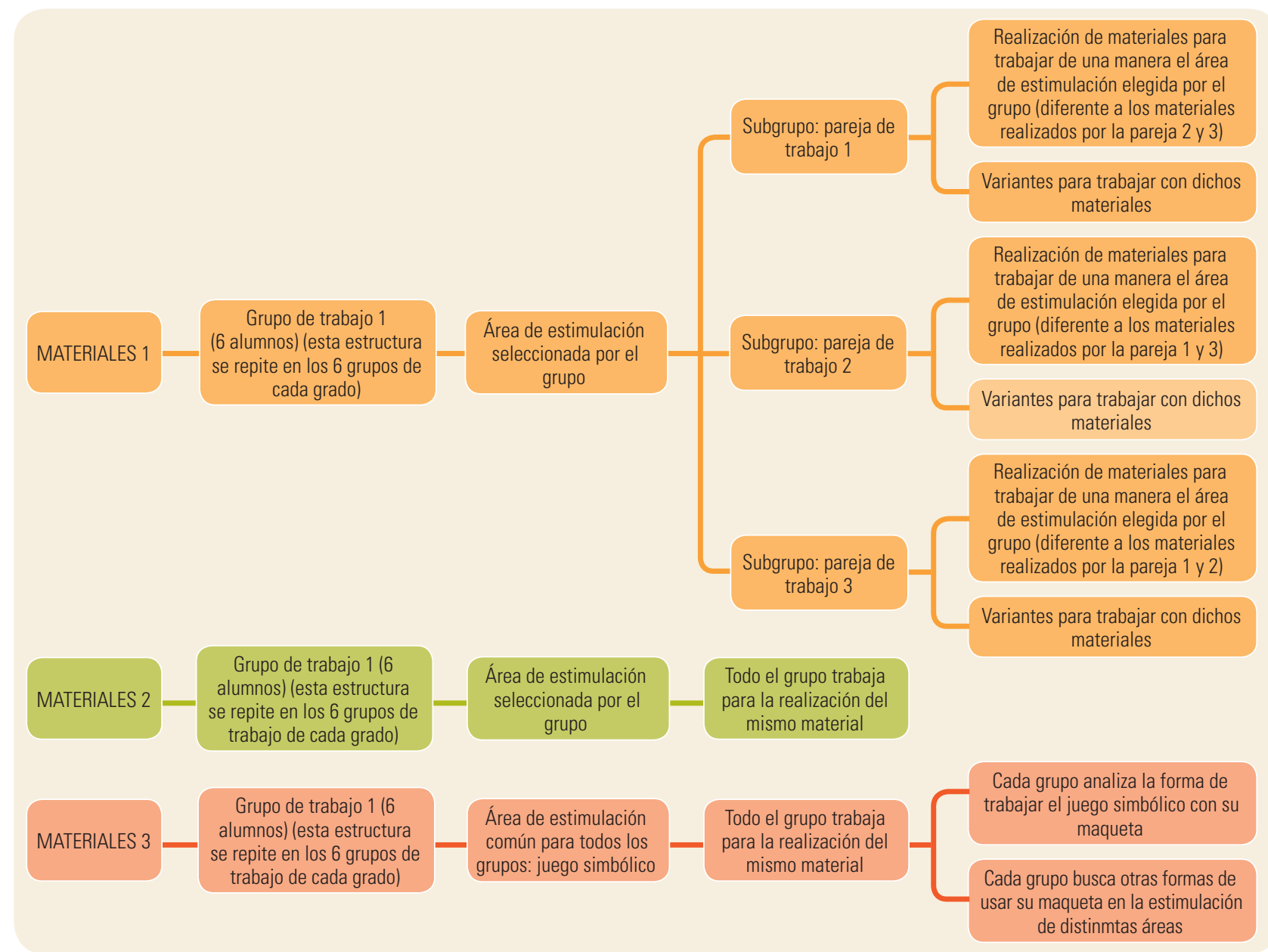

sariamente debía haber un juego con reglas ${ }^{9}$.

- Además, a lo largo del cuatrimestre debían realizar de forma grupal una maqueta para trabajar el juego simbólico, que realizaron sin seguimiento permanente de la profesora y fuera del aula. Las maquetas no se llevarían a Perú por su gran volumen.

Dada la distancia con Perú solo se pudo proporcionar a los estudiantes datos muy generales sobre las características de los alumnos que trabajarían con sus materiales. Además de ceñirse al área seleccionada por el grupo, la única condición que se les puso fue que la

9 Pensar un juego de reglas estimula el pensamiento divergente y el uso de estrategias profesionales distintas a las que se utilizan en el diseño de materiales didácticos. calidad de lo realizado debía ser profesional (acabados, estética, imágenes, soportes...), puesto que iban a ser alumnos reales y vulnerables los que iban a trabajar con ellos. Por tanto, los materiales fabricados deben servir para el objetivo propuesto, deben ser seguros, atractivos, útiles, reutilizables, duraderos, significativos y motivadores.

Por lo demás, se dio absoluta libertad a los alumnos para realizar su trabajo como quisieran, aunque permanentemente se proporcionó feedback sobre la viabilidad hipotética de lo realizado por cada grupo. No obstante, también se dejó una cierta autonomía para persistir en una idea, con la convicción de que de los errores también se aprende.

\section{Curso 2019-20}

Una vez analizada la experiencia anterior, se realizaron algunos ajustes. Duran- 
Esquema 2. Esquema de trabajo durante el curso 2019-2020 ejemplificado con un único grupo

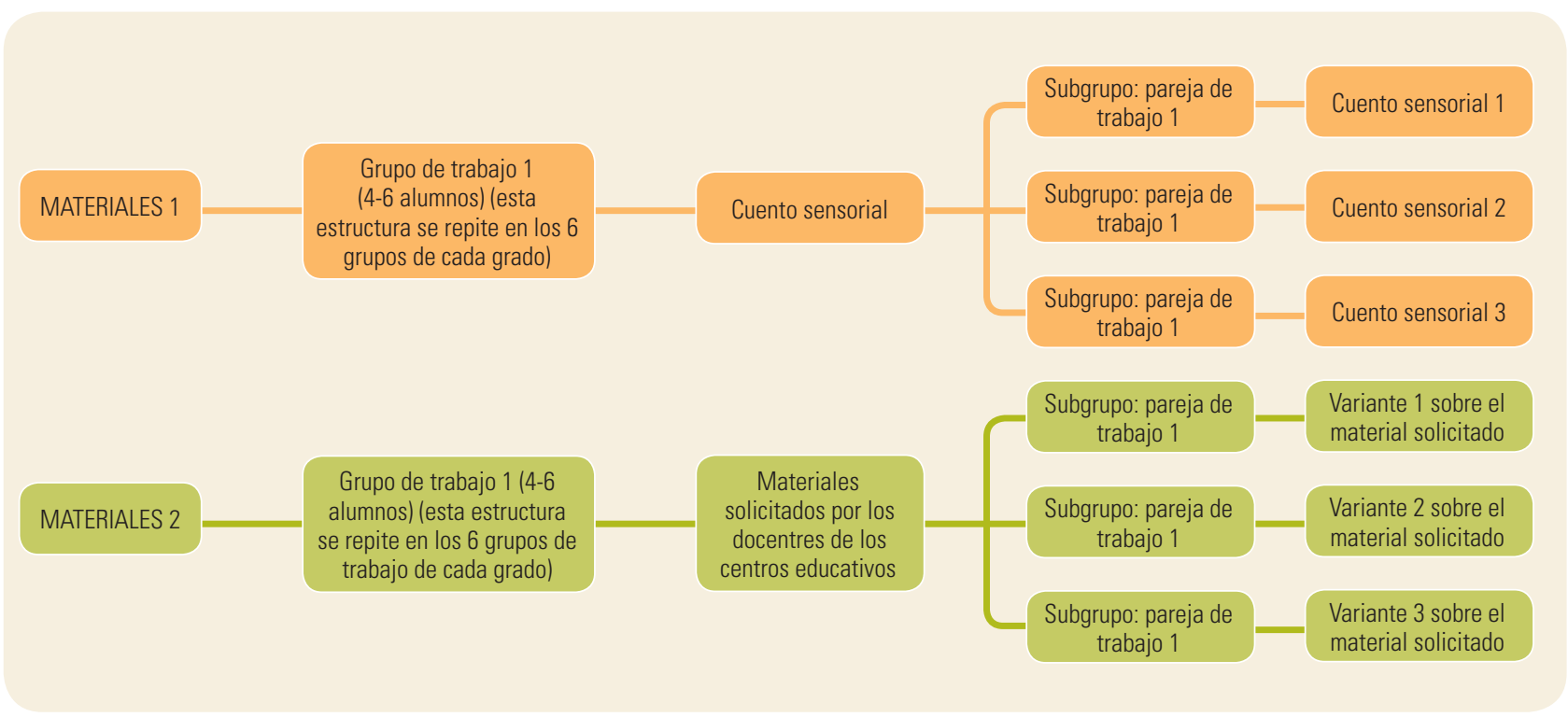

\section{Los alumnos con necesidades de apoyo educativo requieren de recursos variados y con frecuencia adaptados a sus propias características que a veces resulta complicado encontrar en el mercado, son muy caros o no dan respuesta adecuada a las necesidades de estos alumnos}

te este curso, se colaboró con un centro de educación especial para alumnos con diversidad funcional motórica y cognitiva y dos centros de apoyo a alumnos en riesgo de exclusión educativa. La dinámica fue la siguiente: los estudiantes se reunieron con los docentes para que les expusieran sus necesidades y pasaron una mañana con los alumnos del centro al que estaban asignados. Realizaron los materiales y posteriormente, hicieron una presentación a los profesores del centro de lo realizado y trabajaron con los niños y los materiales que les habían hecho. Con ello se pretendía que los estudiantes se enfrentaran a la realidad y pudieran comprobar logros o dificultades.

Esto ha supuesto un cambio radical en la motivación de los estudiantes respecto al curso 2018-19, al tener una idea más ajustada de lo que hacían y para quién lo hacían. En este caso, la materia se es- tructuró en torno a la creación grupal de dos tipos diferentes de materiales (esquema 2):

入 Materiales 1: entre septiembre y mediados de octubre los grupos realizaron varios cuentos sensoriales que fueron solicitados por el centro de educación especial10.

入 Materiales 2: entre octubre y diciembre cada grupo realizó los materiales que les fueron solicitados por los profesores.

De este modo, desde la perspectiva de la profesora de la materia, los objetivos que se pretendieron con esta propuesta fueron:

\section{Enfrentar a los estudiantes a retos cognitivos}

El trabajo comenzaba siempre con la búsqueda de información sobre las características, potencialidades y problemas de los alumnos asignados a cada grupo. Posteriormente se realizaba el análisis del área seleccionada para conocerla más en profundidad, cómo se desarrolla evolutivamente, qué requisitos previos son necesarios, cómo se manifiesta una dificultad

10 Se realizaron solo para el colegio de educación especial ya que en el centro de apoyo los alumnos empezaban más tarde. 
específica, con qué materiales se puede trabajar y cómo puede afectar a aprendizajes posteriores. Una vez realizado este paso, los estudiantes debían decidir libremente y casi sin pautas previas de qué forma iban a trabajar dicha área, defendiendo sus decisiones ante la profesora.

Con todo ello se pretendía sacar a los estudiantes de la "zona de confort"11 a la que estaban acostumbrados (siempre habían trabajado de forma muy pautada, con instrucciones precisas, con objetivos bien definidos...), planteándoles un reto cognitivo en el cual debían comportarse como profesionales, dándoles las normas mínimas y la mayor libertad posible para realizar sus trabajos, siempre que se respetaran los objetivos de la asignatura. Esta situación creó una gran incertidumbre, a veces, un enorme malestar y bloqueo en momentos puntuales. La profesora, además de darles indicaciones precisas sobre lo que hacían, se mostró vigilante para que los estudiantes no olvidaran que "Ios materiales y recursos educativos por sí mismos carecen de valor, ya que este se relaciona directamente con el cómo y el cuánto contribuyen a los objetivos que se pretenden lograr"12.

\section{Conocer la normativa}

Posiblemente sea este uno de los aspectos más complejos, ya que específicamente no hay una normativa al respecto $y$, sin embargo, los materiales que fabrique un profesor deben ser seguros desde todas las perspectivas. Para paliar esta

11 En psicología, la zona de confort se refiere a un estado mental donde la persona utiliza un comportamiento rutinario sin asumir ningún riesgo, instalándonos en nuestra manera de actuar porque nos sentimos seguros. Es una zona que solo abarca lo conocido y nos hace sentir seguros porque todo está bajo nuestro control. El bienestar que se siente no es producto de la satisfacción o el orgullo personal, sino de la ausencia de emociones negativas como la incertidumbre o la inseguridad al refugiarnos en nuestro entorno conocido (extraído de: https://www. psicoadapta. es/blog/que-es-la-zona-de-confort/)

12 https://es.slideshare.net/valderrama332/materiales-y-recursos-educativos
ENFRENTAR A LOS ESTUDIANTES A RETOS COGNITIVOS

1 Comprensión del caso

- Evaluación de necesidades

1 Materiales a crear

- Proceso de creación

1 Forma de uso

REDACCIÓN DE INSTRUCCIONES

1 Nombre del recurso creado

- Fabricación

1 Destinatarios

- Precauciones y normas de seguridad

1 Tipo de aprendizaje que promueve

Instrucciones de uso

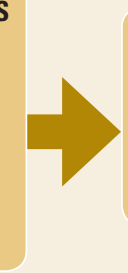

APLICACIÓN DE LA NORMATIVA

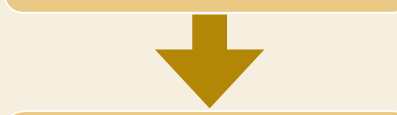

PARTICIPAR EN UNA

EXPERIENCIA DE ApS

1 Al menos con dos centros educativos

- Un centro de habla hispana y otro de habla inglesa

carencia, los estudiantes siguieron la normativa de seguridad en los juguetes.

\section{Creación de materiales}

La creación de los materiales es el objetivo clave de la asignatura, resultando complicado para los alumnos enfrentarse a esta situación, teniendo casi absoluta libertad de acción, aunque tuvieran que justificar sus decisiones profesionalmente. A esta presión se unía el conocer que había niños reales, con problemas reales que iban a usar sus materiales y que con ellos deberían poder mejorar y aprender. Podríamos decir que el exceso de libertad y responsabilidad los aturdió en algunos momentos.

\section{Instrucciones}

Dado que los materiales de apoyo creados iban a ser usados por otros profesores, cada uno de ellos debe incluir un manual de uso $^{13}$ que también iba a ser evaluado en la asignatura. El manual debía incluir las variantes y cómo trabajar con ellas. Esto

13 Los estudiantes tuvieron total libertad en la forma de hacer estos manuales de uso y en su diseño. 


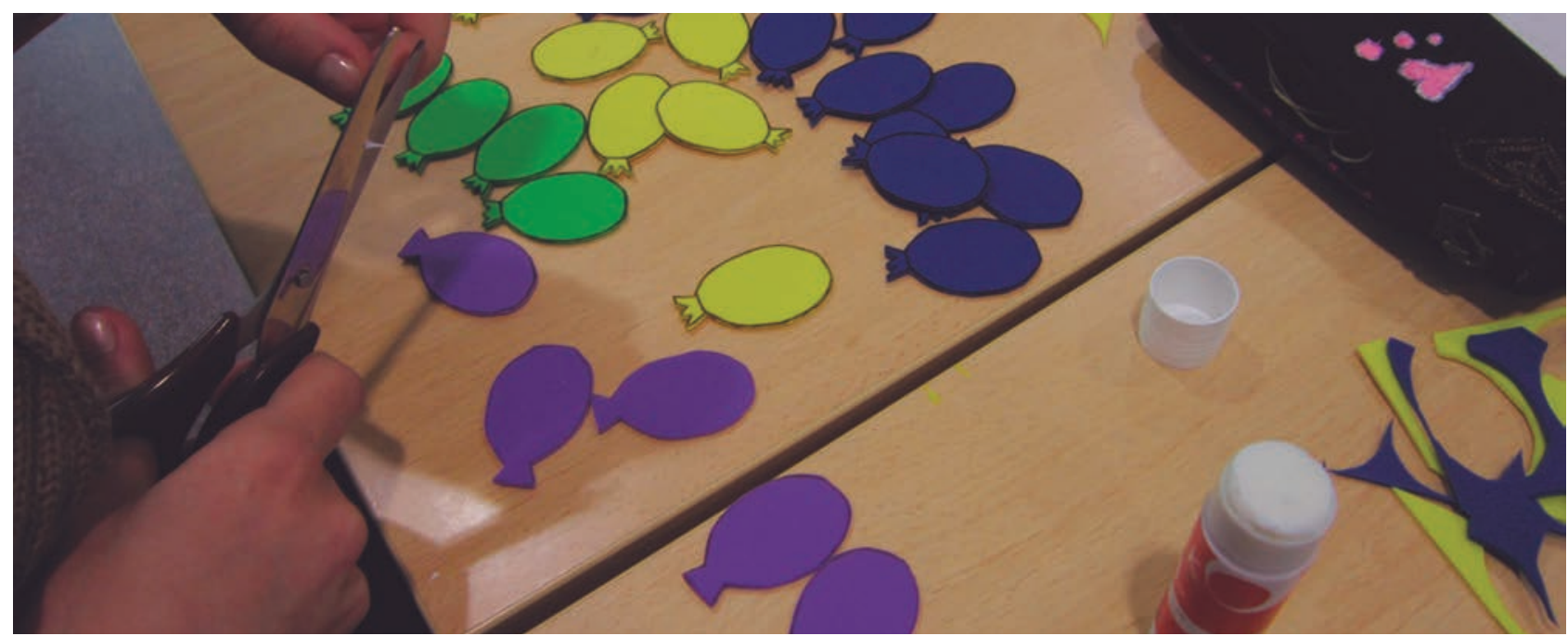

Realización de materiales para enviar a Perú les obligó a repensar sus propios materiales desde diversas perspectivas.

\section{Participar en una experiencia de aprendizaje-servicio}

Como ya se ha mencionado con anterioridad, los alumnos participaron en un ApS proporcionando materiales didácticos a diversos centros educativos.

\section{Compartir los aprendizajes}

El último objetivo pretendido en la asignatura fue posibilitar que todos los alumnos de los grados de educación pudieran conocer los materiales realizados por sus compañeros y para ello se realizó una exposición.

\section{PARA SABER MÂS}

Batlle, R. Aprendizaje-servicio. Recuperado de http://bit.ly/2x|3rvv

Gobierno de Canarias. (S. F.). Criterios para la selección de materiales y recursos didácticos, incluidos los libros de texto. Colegio de Educación Infantil y Primaria "Costa Teguise". Recuperado de http:// bit.ly/3aEdBpp

Méndez, J. M. (2001). Pautas y criterios para el análisis y evaluación de materiales curriculares. Universidad de Huelva. Recuperado de http://bit.ly/2Iz5Yo9

Real Decreto 1205/2011, de 26 de agosto, sobre la seguridad de los juguetes. Boletín Oficial del Estado, n. ${ }^{\circ}$ 209, de 31 de agosto de 2011. Recuperado de https:// www. boe.es/buscar/doc. php?id=BOEA-2011-14252

\section{La calidad de los materiales educativos "analógicos"}

Durante la realización de este proyecto se observó la escasa bibliografía actualizada que existe en relación con la evaluación de la calidad de los materiales didácticos realizados artesanalmente y no comercializados. Habitualmente se han encontrado referencias a herramientas más tradicionales (vídeos, libros/ libros de texto, cine...) o a recursos informáticos realizados con fines educativos. En estos momentos parece que lo más innovador es usar las TIC hasta la extenuación. Sin embargo, se deberían considerar opciones diferentes para poder trabajar en entornos no tecnológicos con alumnos con dificultades de aprendizaje o diversidad funcional que son previas al trabajo en entornos digitales.

Con este fin se desarrolló una lista de chequeo (check list) con todos los ítems que la profesora iba a evaluar en la asignatura y que se relacionan directamente con la calidad de los materiales realizados •

\section{HEMOS HABLADO DE}

\section{DIY; maestros; estudiantes grado educación; materiales; retos; dificultades aprendizaje; seguridad materiales; aprendizaje-servicio.}

Este artículo fue solicitado por PADRES Y MAESTROS en septiembre de 2019, revisado y aceptado en febrero de 2020. 